\title{
Investigation of the Blockchain's Influence on Traditional Banking: Challenges and Opportunities
}

\section{Simona Pakenaite (Independent Researcher)}

Faculty of Business Management,

Vilnius Gediminas Technical University, Vilnius, Lithuania

Kamile Taujanskaite (PhD)

Department of Finance Engineering, Faculty of Business Management,

Vilnius Gediminas Technical University, Vilnius, Lithuania

Doi:10.19044/esj.2019.v15n10p1 ～URL:http://dx.doi.org/10.19044/esj.2019.v15n10p1

\begin{abstract}
New technologies is constantly becoming more and more important for our dynamically changing society, and it occupy greater importance of nowadays' financial sector. This paper focuses on the investigation of the Blockchain and its impact on traditional banking in a qualitative way. The theoretical part of the research presents general overview, brief technical operating principles, main risks, and opportunities of the decentralized networking. The second part examines key properties, main limitations, pros and cons of the Blockchain as well as wider applicability in the financial sector based on experts' evaluation. The results of the expert evaluation provides core records about bank weaknesses and key aspects of the Blockchain influence for financial sector in conformity with 32 professionals. Findings of the research are very relevant while technologies are emerging enormously. Bank collaboration (and not the competition) with fintech is indispensable since both have strengths and weaknesses. However, new technologies, especially peer-to-peer computing, continually gains attention (positive or negative) from the researchers, media, and public. Methods used in the research are: scientific literature analysis, statistical data analysis, comparative analysis, and expert evaluation.
\end{abstract}

Keywords: Blockchain, Fintech, Cryptography, Decentralization, Banking, Expert evaluation

\section{Introduction}

Even though the first and most popular decentralized digital currency was introduced in early 2009 (Nakamoto, 2009), however, people talked about it and first attempts already appeared in the last century. In 1983, David Chaum 
proposed theoretical insights about the use of cryptography in untraceable electronic payments. Although, the phenomenon accelerated and gained popularity after Bitcoin was introduced, or even more precisely, when cryptocurrencies started to use an open source program called Blockchain. The first attempt to analyze this technology was in 1991 - S. Haber and W. S. Stornetta in their research described a cryptographically secured chain of blocks (Narayanan et al., 2011). Blockchain is a decentralized transaction and data management technology which was developed first for Bitcoin cryptocurrency. The interest in Blockchain technology has been increasing since the idea was coined in 2008 (Yli-Hummo et al., 2016). The effect of this technology on the public authorities, financial markets, and banking sector is inevitable since the Blockchain gained such popularity. The aspects of distributed ledger are globally discussed not only by the investors, but also by the society, policymakers, economists (Al-Laham et al., 2009), and even national governments. Experts identify Blockchain as the disruptive forthcoming innovation due to the ability to apply it to many other areas since the immutability is ensured in applications beyond cryptocurrencies (Tapscott et al., 2016). As a result, the influence of the new technology is highly increasing by affecting many domains such as humanitarian, social, scientific, and especially the financial sector. Therefore, the Blockchain is becoming the embedded economic layer for the Web system, and it is serving as the technological base for decentralized payments and exchanges, digital asset invocation and transfer, smart contract issuance and enforcement, etc. (Swan, 2015). Some authors (e.g. Vajačka, 2014; Glaser, 2014) identify Blockchain as the next major technology following Internet and social networking with the ability to change humans' activity completely. The main aim of the Blockchain is to compose a decentralized environment where no third party (intermediary) is responsible for the transactions and data (Yli-Huumo et al., 2016).

Furthermore, the object of this analysis is the Blockchain technology. The goal of investigation is to analyze possible influence of decentralized networking for conventional financial procedures in a qualitative way. Wherefore, the article investigates presumptive influence of the Blockchain on traditional banking by considering main qualities, risks/opportunities, and its advantages/disadvantages. This is in accordance with professionals from tech, banking, financial, and related sectors.

Methods used in the article comprise of the following: scientific literature analysis, statistical data analysis (T-test), comparative analysis, and expert evaluation. 


\section{BLOCKCHAIN: BRIEF OVERVIEW OF THE TECHNOLOGY}

Blockchain was introduced as a virtual currency system that could change central authorities for issuing money units, making ownership trades, and confirming transactions. The system was created for Bitcoin as it is the first application of this network (Nakamoto, 2009). Since the establishment of the Internet it is considered to be the most tempting invention. The Blockchain simply could be defined as an open - source system or public distributed ledger that efficiently records transactions between two parties in a verifiable and permanent way and it is completely open to every user (Iansiti, 2017). All information about transactions and records of value or assets is included in blocks which are chronologically added into the chain in a linear way. All blocks are enclosed and when the trades are completed, Blockchain increases. Furthermore, a copy of Blockchain is automatically sent to nodes (computers, which are part of the system) when they join the network. All nodes prove that the block is truthful by ensuring trust between parties in a system. The whole Blockchain contains reports on each transaction that occurred, where relevant information can be found, such as precise details about the trade value which belonged to a particular address some time in the past (Nair \& Sebastian, 2017).

Additionally, technically decentralized technology consists of: peer-topeer networks, public-key cryptography, and distributed consensus mathematical algorithms. Every block in a system stores not only relevant information as mentioned before in this chapter but also a hash, which is always unique and identifies block with all its content. In accordance to $\mathrm{Z}$. Zheng et al. (2018), each block points to the immediately previous block through a reference that is essentially a hash value of the previous block called parent block. Every change in the block changes the hash, and what this means is that it is no longer the same block. Moreover, every block includes a hash from a previous block (i.e. each block references previous one) which creates a chain and makes a Blockchain secure (Narayanan et al., 2011) (Figure 1).

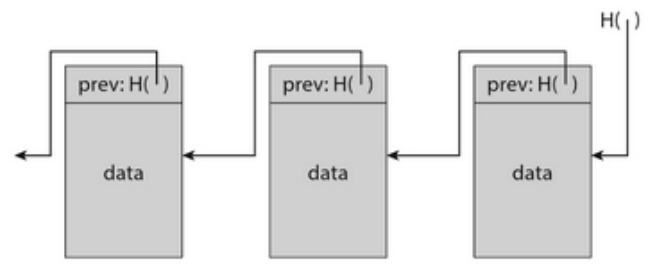

Figure 1. Structure of Blockchain (Narayanan et al., 2011)

If there occurs a tamper with one block, the revision of all blocks is required due to a mismatch in the chain. Security in a Blockchain occurs because of the hashing and a proof-of-work without public intermediary 
needed. Cryptography in the centralized networking provides a mechanism for coding rules that helps to avoid the equivocation and falsification.

Advantages and Disadvantages of Blockchain: The usage and implementation of Blockchain has some opportunities and obstacles. The biggest benefit of this network is disintermediation. Blockchain also provides direct transactions without any central administrator. Moreover, all transactions are carried out all the time (there are no working hours) and it takes less time for clarification and verification compared to banks particularly when cross-border transactions are made. In fact, this allows Blockchain to operate within the whole area of the digital world by allowing any kind of transactions to be securely made. Data shared in the Blockchain is complete, sequential, accurate, and generally available. Also, all transactions made are immutable and transparent because of the cryptography which ensures trust between different parties. Furthermore, this network creates room to simplify ecosystem of trades and to avoid complications of multiple ledgers. This is because every transaction is added to the same one ledger. Therefore, the Blockchain could become the embedded economic layer for the Web system, serving as the technological base for decentralized payments and exchanges, digital asset invocation and transfer, smart contract issuance and enforcement, etc. (Swan, 2015).

Nevertheless, Blockchain has a complex verification and generation technique. Every transaction in the ledger should be digitally signed by a public-private key cryptography. Since network operates in peer-to-peer way, it is essential for Blockchain to ensure trust in the exchanges. Moreover, there is a need to guarantee that all nodes of the system reach a consensus. This requires a lot of back-and-forth communication and it claims a lot of computer power. Also, faster trade verification causes bigger transactional fees, which is paid to miners. Besides, there are a lot of legal issues and societal issues in trust.

Recently, Blockchain technology attracts more and more attention not only from practical point of view, but from scientists also. Many researches investigate various issues connected with Blockchain.

Despite all of this, there is a lack of investigations on the effects this innovative technology could have for traditional banking. Peters and Panayi (2015) have discussed that Blockchain is disrupting the world of banking and that the technology could be applied to many areas even for clearing services and settlement assets and not only financial areas. M.Morini (2016) also indicated that there are actual business cases e.g. collateralization of financial derivatives that could incorporate decentralized networking to reduce costs for clearing houses and risks for counterparties.

Centralized vs Decentralized Exchange Systems: All contracts, transactions, and other operations in the economy are managed by public or 
private authorities, in other words, central institutions. They protect properties and rights as well as set organizational boundaries, verify identities, and ensures transparency. They also manage interactions between institutions, society, or individuals. However, Blockchain provides a possibility for decentralized exchange system without any intermediary. As it was mentioned in the previous chapter, everything is recorded in a public ledger available for everyone. All transactions trades in the network are approved by the users. Therefore, there is an ever increasing active interest in the Blockchain technology of IT start-ups, financial centers, and investment that banks proposes. This means that there will be significant changes in areas such as intermediation, custody of securities, settlement, and compliance. With Blockchain, every contract is involved in shared network and has digital code as well as signature that could be validated, identified, and shared in peer-topeer network. All individuals, institutions, and algorithms would easily interact with each other. On the other hand, a lot of barriers such as technological, organizational, and governance would fall. This is a huge potential of Blockchain. Moreover, it is a foundational technology, which means that Blockchain has the feasibility to establish new substructures for both economic and social systems. However, it will take a lot of time to adopt the technology to replace existing infrastructures - it is a progressive and constant process (Iansiti, 2017).

\section{METHODOLOGY OF EXPERT EVALUATION}

Since the interest as well as the influence of the decentralized network is significantly growing, the attitude and position of experts is indispensable. The research includes qualitative analysis by employing expert evaluation method. This method usually formulates scientific concepts, seeks for scientific objectivity as well as predicts aims in particular phenomenon (Tidikis, 2003). Also, it is used when there is no possibility to get knowledge from literature. In general, expert evaluation method is a procedure, which allows for conciliation of the different opinions of the experts and it composes of one solution or explanation. This method is the aggregated opinion of an expert group based on their experience, expertise, analysis, and intuition. In accordance to K. Kardelis (2005), the essence of expert evaluation is that experts logically analyze relevant problem by evaluating available data on a quantitative basis. Additionally, expert evaluation method's reliability depends on the selection of the participants. An expert is defined as a person who has the highest competence and the most reliable and sufficiently detailed information about the problem under the particular field, because of his professional or life experience (Tidikis, 2003). They should be qualified and have the capacity to analyze problem without the interference of prevailing tendencies. In addition, the reliability of expert evaluation method depends on 
the size of a group, diversity of interest areas of experts as well as individual qualities. Hence, a lot of attention is devoted to the selection of professionals for the analysis under the relevant topic, and post hoc screening is required as well. The assumptions of the expert evaluation (Tidikis, 2003) are as follows:

- An expert has accumulated a large amount of relevant information (an expert can rely on his/her own intuition since he/she has a lot of knowledge in a particular area). Therefore, an expert can be a source of qualitative information;

- The attitude of the expert group is similar to the actual problem solution;

- A decision is only obtained in the context of the compatibility and reliability of expert opinions.

Data Collection and the Respondents: After considering the interviewer's capacity and availability of sources and information, active individual interview method was chosen as the most suitable way to collect data. A survey was employed as a tool to gather responses. Therefore, the questionnaire was composed of three main parts which include multiplechoice, open-ended questions, close-ended questions, and Likert-scale: (I) 3 questions related with the Blockchain, (II) 1 question related with banks, (III) 2 additional socio-economic questions was included as well to evaluate respondents' suitability. Professionals were selected based on self-assessment of their competence in the expertise (Tidikis, 2003). Afterwards, all respondents were screened by evaluating their experience and occupation.

Additionally, as it is shown in Figure 2, to get acceptable level of confidence, not less than 15 respondents should be included in the research. The confidence level must not be less than $80 \%$ to conduct responsible and competent analysis (Rudzkienè, 2014).

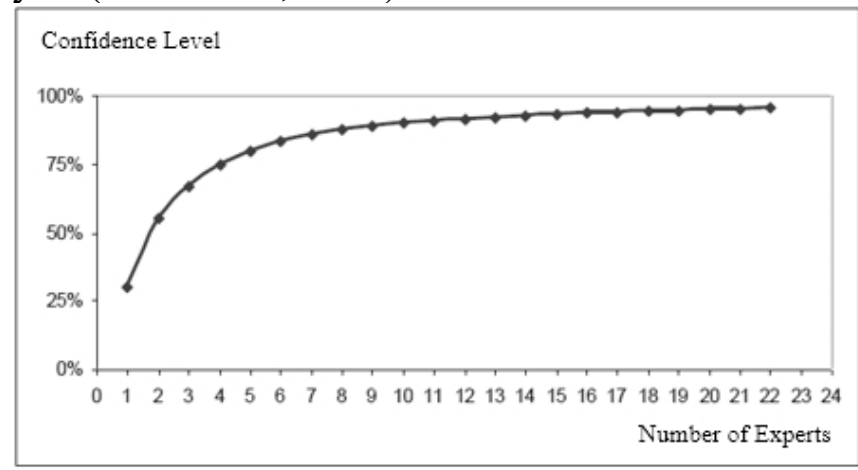

Figure 2. Confidence Level of the Analysis in Accordance with Number of Experts Included (Rudzkienè, 2014)

As the graph suggests, the more respondents are included in the research, the more valid and plausible analysis can be exercised. Moreover, questions 
for experts were conducted in accordance with the analyzed literature. Nevertheless, professionals were able to include their own attitude based on the experience and knowledge under the particular matters. This leads to a more extensive and profound study.

Paired T-test for Reliability Checking: The third assumption of expert evaluation states that the analysis can be conducted only with the compatible and reliable attitudes of the respondents. Consequently, the Paired T-test was selected as the best way to check for the suitability of the responses. This is because the questionnaire includes several types of matters where other methods do not apply.

Hence, the Paired T-test is a statistical method for comparing quantitative outcomes between two groups. Since the different observations of Expert Evaluation are applied for the same subject, the paired T-test was selected. The main assumptions are:

- Sample can be divided into paired observations: $\left(X_{i 1}, X_{i 2}\right), i=$ $1, \ldots, n$;

- The differences between the two observations are normally distributed with mean $\mu_{d}$.

- The observations are independent of each other.

Null hypothesis of Paired T-test: $H_{0}: \mu_{1}=\mu_{2}$ is equivalent to $H_{0}: \mu_{d}=0$ (where $\mu_{d}$ is the difference between paired observations). The null hypothesis defines that the true mean difference $\left(\mu_{d}\right)$ is equal to zero and there is no statistical significance between means (Forman, 2017). Under this hypothesis, all observed differences are explained only by a random variation. The alternative hypothesis must be constituted as well. However, it controversially assumes that the true mean difference between the paired samples is not equal to zero. Observations of the question is identified as reliable when the observed differences are explained not by a random variation. As a result, the null hypothesis is eliminated and an alternative one is confirmed (Pallant, 2010).

\section{ANALYSIS OF THE BLOCKCHAIN INFLUENCE ON TRADITIONAL BANKING: EXPERT EVALUATION}

To obtain broad profile of the qualitative analysis, the questionnaire was sent to the experts from different professional areas as well as other countries. As a result, 37 responses were gathered in this research. However, to clarify the observation, participants were screened and only the most reliable ones (32 respondents) were included in the analysis. Moreover, Figure 3 below shows the geographical distribution and occupation areas of respondents. 


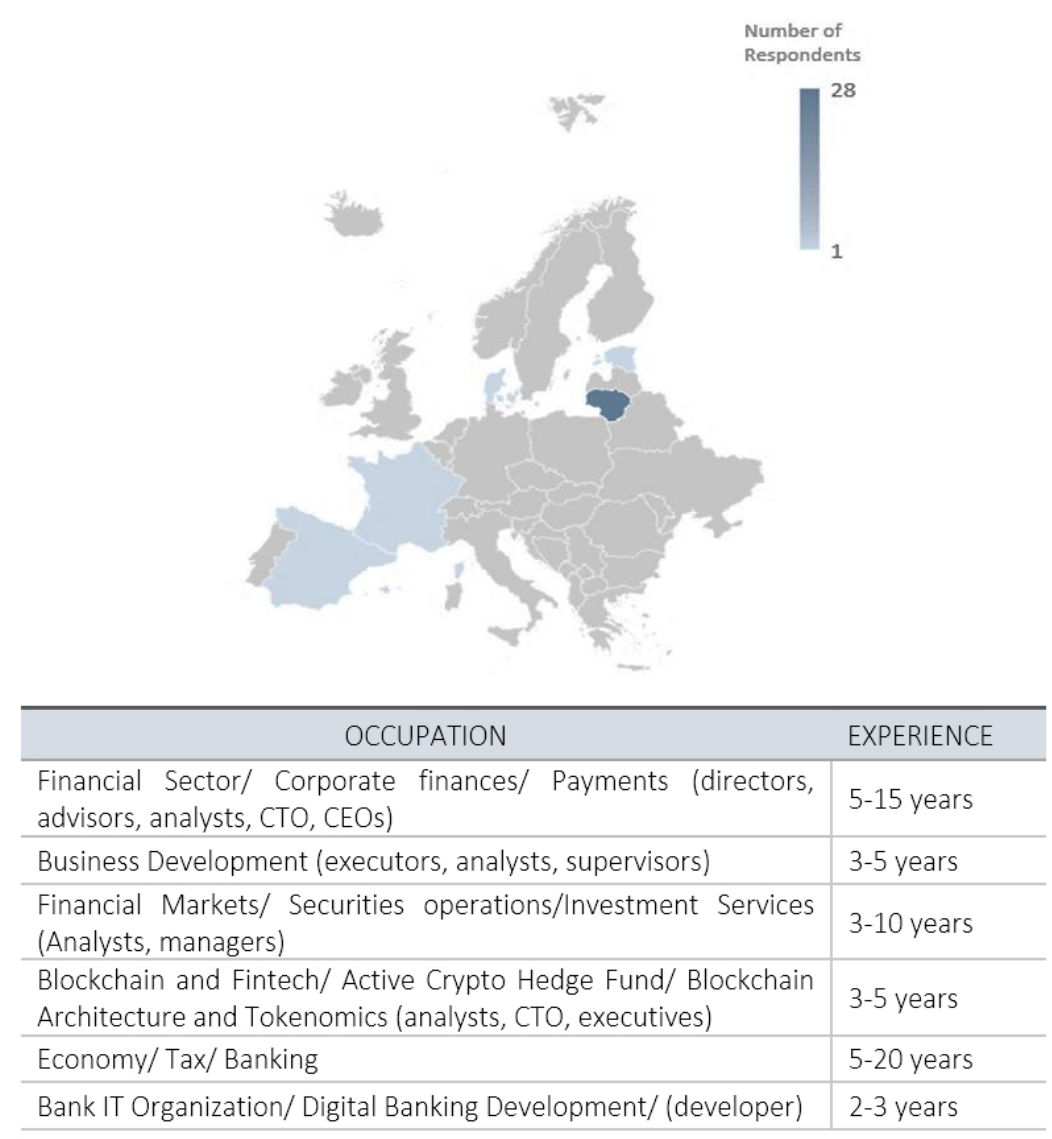

Figure 3. Profile of the Experts (Created by an Author)

With the first matter, experts were asked to underline the main limitations of the Blockchain implementation in the financial sector. Furthermore, Figure 4 indicates percentage distribution of the collected responses. A large majority of the experts indicate that the main risks of the Blockchain's implementation in the banking sector is lack of standards and regulation $(30.86 \%$ of all points given) as well as legal and regulatory compliance (22.22\% of all points provided). Moreover, the Blockchain has the property to cross jurisdictional boundaries, as the activity on this ledger can be located anywhere in the world. This can cause complicated legal issues that require careful consideration in relation to the relevant contractual relationships. In addition, in a traditional banking transaction, if the intermediary is at fault irrespective of the transacting mechanism or location, the bank might be sued and the legal issues will be contractually governed (McKinlay, 2018). 

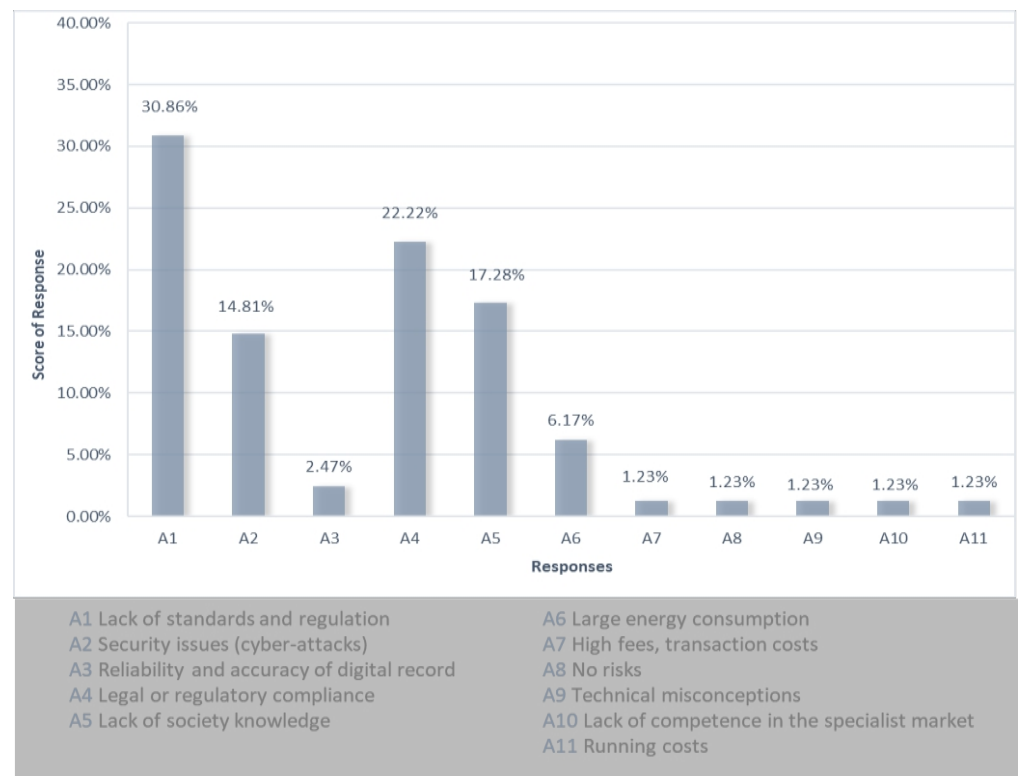

Figure 4. Question 1: The Main Risks of the Blockchain (Created by an Author)

Nonetheless, in a decentralised environment, it may be difficult to identify the needed set of rules that should apply, especially when distribution is anonymous (Czamecki et al., 2016). Consequently, Blockchain could cause legal and regulatory incompliance. Governments do not support decentralization and try to establish certain regulatory measures. Lack of society knowledge (17.28\%) is designated as the third risk of the Blockchain's spread. People are getting more and more interested in the distributed ledger, but there is still a huge gap of knowledge for Blockchain to be adopted more widely. In addition, even $14.81 \%$ of respondents identify security issues (cyber - attacks) as one of the most reliable limitations of the distributed ledger. However, today if a cyber-attacker gets an access to the Blockchain and the data of the network, this does not necessarily mean that he can access all the information. In accordance with one of the expert's findings, private and public Blockchain should be considered here. This is because substantial differences appear when talking about security, efficiency, and scalability. The key difference between public and private Blockchain is concerned with who can participate in the network, execute the protocol, and maintain the shared ledger. On one hand, a public Blockchain is open and anyone can participate in the networking. A private Blockchain, on the other hand, requires an invitation and must be confirmed either by the network starter or by a set of rules put in place (Jayachandran, 2017). Nevertheless, the cyber insecurity still exists. According to the experts' attitude, the least significant limitations are reliability and accuracy of digital record. A large majority of specialists indicates Blockchain as a reliable and accurate networking because of its 
complex operating principle and immutability. However, experts added some more qualifications such as technical misconceptions, lack of specialists in fintech, and high running costs that indicate even more limitations of the Blockchain's implementation in financial sector.

Subsequently, the next question is related with the most important features of the Blockchain that could be used by implementing it in a banking industry. Experts were asked to rank key properties of distributed ledger on a scale from 1 to 5 . The most important property of the Blockchain in accordance with professionals is decentralization and immutability. The distributed ledger provides direct transactions between parties and no intermediary is needed as a central administrator. Thus, once the transaction is preceded it could not be copied, changed, or deleted because of its operating principle. Also, the third key property of the Blockchain, in accordance with the experts, is security. Respondents explain that the Blockchain could help to increase security of personal data, duplication, and misleading information as well as to reduce human error. By deliberating the cost-effectiveness, time saving and money saving are defined as the most important aspects. Labour saving scores less but is still considered as a very important part of the Blockchain's properties for traditional financial industry. In accordance with Cocco, L. et al. (2017), the conventional financial sector employs many operative costs to run systems of certain activity more efficiently. These costs involve time and money invested in infrastructure, electricity, and automatization. Contrarily, systems based on the Blockchain are only connected to one network, which reduces waste of the office materials, humans' time, and money invested in the infrastructure. In other words, Blockchain simplifies the framework of financial activities and reduces costs by employing distribution of the ledger.

Moreover, participants presume that by adopting decentralized networking in the banking area, it helps to increase efficiency and transparency. This is due to the availability to share reliable data between authorized users without the ability to duplicate or counterfeit references. Information of the Blockchain is also public and accessible for all users, which increases clarification of the shared data and other activities. Better accessibility is considered as the last property with the least effect on conventional banking.

Consequently, the following part of the survey mentions the advantages of the Blockchain which could be brought to the banking industry (what is the most needed that banks cannot ensure). 21\% (Figure 5) of experts denote that the main benefit which distributed networking could bring to the banking industry is quicker transactions. The second and the third benefit are transparency and trust as well as disintermediation. The Blockchain can optimize the global financial infrastructure by achieving sustainable 
development with efficient systems, quicker and cheaper transactions as well as data distribution without any centralization at the international level. Moreover, professionals indicated that by adopting the Blockchain, banks could reduce its transaction and running costs. Also, $13 \%$ of respondents deem that the distributed ledger could reduce the number of human error because the information is digitalized and recorded in the nodes of the network in the consistent order.

9\% of the experts also assume that the Blockchain could improve security. However, quality assurance, anonymity, and elimination of correspondence banks are the least required benefits of Blockchain. Yet, they are still identified in the literature as this could bring important benefit to the conventional financial sector.

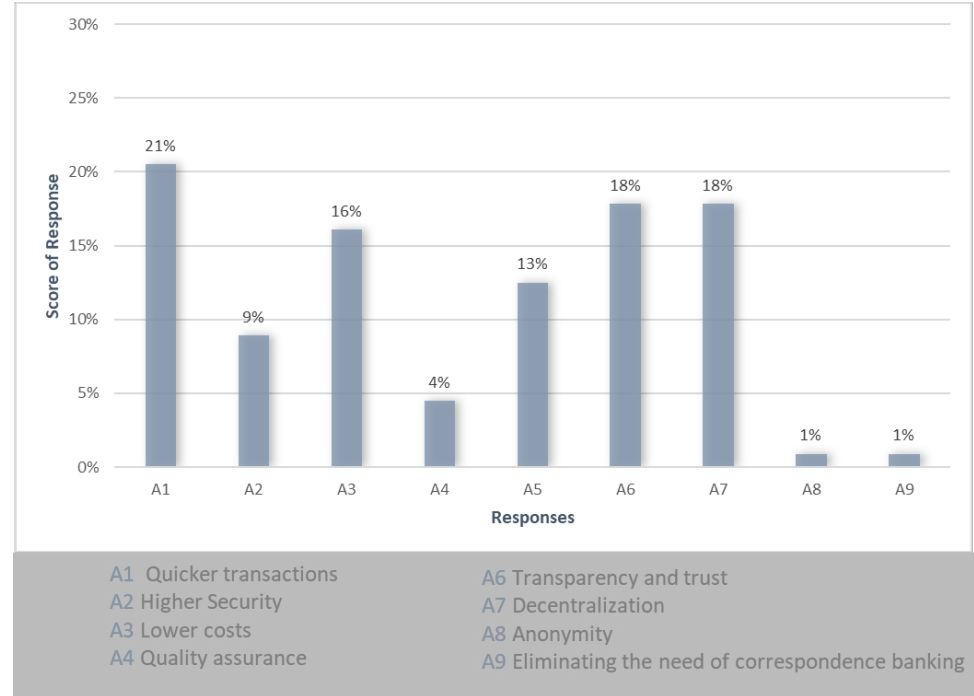

Figure 5. Question 3: Benefits of the Blockchain (Created by an Author)

Additionally, experts specified three weaknesses of the banks. The most frequent provision is that banks are over-regulated nowadays. Professionals determine that banking industry has large administrative burden due to overregulation, susceptibility to disruption (growing competition from non-banks, fintech firms), too much bureaucracy and lack of digitalization. Besides, experts determined that banks are over structured and afraid of any changes: no motivation/appetite for innovation - limited new service/product offering. A professional stated that banks are "too big to move". It takes a lot of time to adopt the fast-changing environment and the banking sector is unavailable to change and adjust to the market. Also, in accordance with wide profile experts, result shows that banks proceed with a high transaction costs, especially for the small users: significant part of revenue is still earned on commission (e.g. for bank transfers), which is not sustainable in medium term future. Similarly, banking industry was said to be slow in response, having 
enormously long transactions outside SEPA (up to few days) with a high regulation cost. Likewise, banks were identified as inflexible and they lacked transparency. Experts provided some of their own insights regarding banking weaknesses:

1. The existing standards were built in the 70-80s: The SWIFT network and the whole correspondence banking are unable to work efficiently in the 21 st century. Ripple network should sweep such away once it is implemented.

2. The whole e-commerce standard that is built on payment card processing is inefficient and costly because of the core technological issues related to the PULL method of transferring assets from VISA/MC.

3. Banks (excluding the finech from the list) became sluggish in onboarding any of the innovation to their business model. However, the progress and evolution does not work this way.

Accordingly, vast majority of experts (even $63 \%$ of all participants) designates that banks lack transparency nowadays. In accordance to the European Central Bank (European Central, 2018), transparency is described as: when "bank provides the general public and the markets with all relevant information on its strategy, assessments, and policy decisions as well as its procedures in an open, clear, and timely manner". In other words, transparency appears when all relevant information (periodic performance, financial position, business model, governance, risks of banks) is completely and easily available to the public. Components of transparency include publicly available accounting information, information intermediaries such as financial analysts, credit rating agencies, and the media, supervisory disclosures (including stress-test disclosures), banks' voluntary disclosures, and information transmitted by securities prices (Bushman, 2016). Controversially, 31\% of respondents identifies that banks run their activity with the transparency. However, another group of respondents $(6 \%)$ are in between. They state that apart from the fact that there are some unclarified changes regarding fees and uncertainty in transactions, etc. banks are quite transparent. It has so many exceptions and regulations that, in some cases, it is complicated to perform in a very transparent way. Furthermore, some respondents stated that bank's transparency relies on the owner of a bank and some other aspects.

\section{SWOT Analysis Blockchain Applicability}

To get more accurate picture of Blockchain's impact on financial sector, its pros and cons, and risks and opportunities, SWOT analysis was conducted in relation with the findings from expert evaluation analysis (Figure 6). 

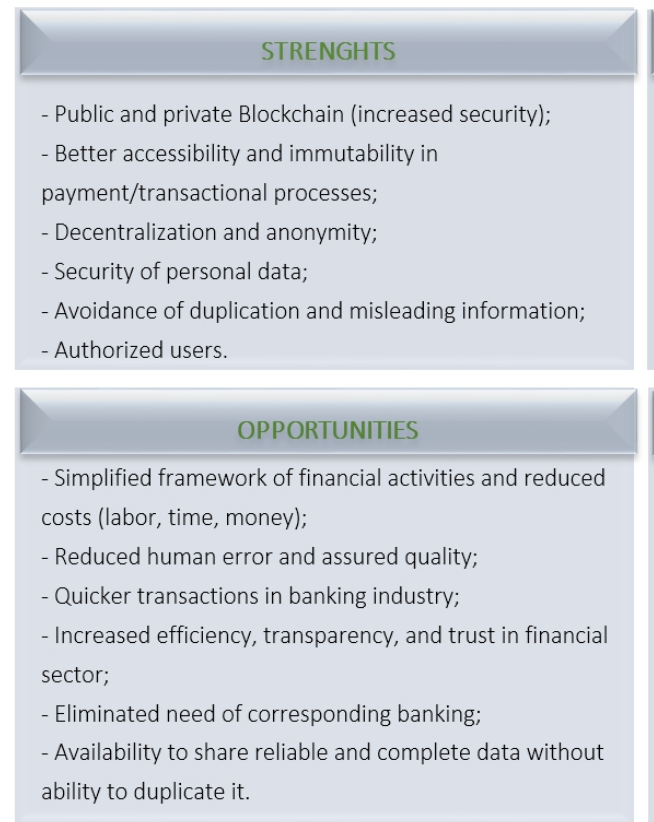

\section{Figure 6. SWOT Analysis of the Blockchain's in Relation to Financial Industry}

The analysis shows that the Blockchain is seen more as a foundational technology with many opportunities and strengths rather than weaknesses. However, it is a new technology and it will take years for business to adopt it and change the economy. There are two dimensions that affect how technology and its use in business evolves. The first one is novelty - how the technology is new to the world. The newer it is, the more effort is required to adopt it and it takes more time for users to understand what problems technology could solve. The second one is complexity - the number and diversity of parties that is involved to produce value with the technology (Iansiti, 2017).

\section{Conclusion}

To sum up all respondents' provisions, a vast majority of experts sustain the Blockchain as a future technology which can significantly improve traditional banking sector by providing quicker and cheaper transactions, costeffectiveness, time, and money savings. Also, they indicated that Blockchain can ensure trust and higher transparency for financial sector, since more than half of the respondents identified that banks lack clarification nowadays. Greater transparency in the provision of public information and changes to internal controls within banks is a must.

Furthermore, some professionals indicate Blockchain technology as the most prevailing IT trend and consider it to be the most tempting invention 
since the Internet. Key properties of the Blockchain are decentralization and immutability. It also helps to protect data and information from counterfeiting, changing, and double sending without any intermediary. However, the high dependency on technology and the WEB today has introduced new business models and revenue flows for enterprises. Although this new gaps provide opportunities for cyber attackers to exploit, it also has other limitations such as lack of standards and regulation, legal and regulatory compliance, deficiency of society knowledge, etc. Therefore, the distributed networking does not require any intermediation and it is not based on any state or government. It is only founded on trust between different parties. Nonetheless, it causes huge governmental and legal concerns. Lack of society knowledge and specialist in this area are very important limitations for Blockchain to spread out, which restricts applicability of the technology in a more broad way. However, Blockchain is in its initial stage, which means it needs adjustments. For example, it cannot encompass large amount of transactions at the same time. Even so, Blockchain is evolving very quickly and can be adopted in many various areas. Considering professionals' findings, the Blockchain has a huge influence for the conventional financial sector and the effect of the technology is increasing enormously. Nevertheless, it will take a lot of time to adopt the technology to replace existing infrastructures since it is a progressive and constant process.

\section{References:}

1. Chaum, D. (1983). Blind Signatures for Untracable Payments; Advances in Cryptology. University of California Santa Barbara USA.

2. Cocco, L., Pinn, A., \& Marchesi, M. (2017). Banking on Blockchain: Costs Savings Thanks to the Blockchain Technology. Journal Future Internet, 1-21.

3. Digital Asset Platform (2017). Retrieved from Digital Asset: https://www.digitalasset.com/technology

4. European Central Bank (2018). Retrieved from ECB: https://www.ecb.europa.eu/ecb/orga/transparency/html/index.en.html

5. Forman, J. (2017). T-tests and Hypothesis Testing; Basic statistics for Experimental Researchers. Copenhagen: University of Copenhagen.

6. Iansiti, M. L. (2017). The Truth about Blockchain. Harvard Business Review.

7. Jayachandran, P. (2017). The Difference Between Public And Private Blockchain. Retrieved from IBM: https://www.ibm.com/blogs/blockchain/2017/05/the-differencebetween-public-and-private-blockchain/

8. Kardelis, K. (2005). Moksliniu tyrimu metodologija ir metodai, III leidimas. Šiauliai: Lucilijus. 
9. Krzysztof Wojdyło, J. C. (2016). Blockchain, Smart Contracts and $D A O$. Wardyński \& Partners.

10. McKinlay, J. (2018). Blockchain: Background, Challenges and Legal Issues. Retrieved from Dla Piper/Publications: https://www.dlapiper.com/en/denmark/insights/publications/2017/06/ blockchain-background-challenges-le

11. Morini, M. (2018). Decentralized Financial Markets. Torino: Banca IMI - Intesa San Paolo Group.

12. Nair, G. R. \& Sebastian, S. (2017). Blockchain Technology; Centralised Ledger to Distributed Ledger. International Research Journal of Engineering and Technology.

13. Nakamoto, S. (2009). Bitcoin: A Peer-to-Peer Electronic Cash System Bitcoin.

14. Narayanan, A. B. (2016). Bitcoin and Cryptocurrency Technologies: A Comprehensive Introduction. United Kingdom: Princeton University Press.

15. Pallant, J. (2010). SPSS Survival Manual: A Step by Step Guide to Data Analysis Using SPSS. Maidenhead: MC Graw Hill:Open University Press.

16. Peters, G. P. (2015). Understanding Modern Banking Ledgers through Blockchain.

17. Rudzkienè, V. (2014). Darnaus vystymosi tyrimu metodologija ir metodai. Vilnius: Vytauto Romerio Universitetas.

18. Song, W. (2016). Advantages \& Disadvantages of Blockchain Technology. Retrieved from Blockchain Technology: https://Blockchaintechnologycom.wordpress.com/2016/11/21/advant ages-disadvantages

19. Swan, M. (2015). Blockchain: Blueprint for a new economy: First Edition. New York: O'Reilly Media.

20. Tidikis, R. (2003). Socialiniu mokslu tyrimu metodologija. Vilnius: Lietuvos Teisi4s Universitetas.

21. Vajačka, M. (2014). Basic Aspects of Cryptocurrencies. Journal of Economy, Business and Financing, 75-83.

22. Zaninotto, F. (2016). The Blockchain Explained to Web Developers, Part 1: The Theory. Retrieved from Marmelab: https://marmelab.com/blog/2016/04/28/blockchain-for-webdevelopers-the-theory.html

23. Zheng, H. S. (2017). An Overview of Blockchain Technology: Architecture, Consensus, and Future Trends. 2017 IEEE 6th International Congress on Big Data, BigData Congress. Mendeley. 